optimizing goodness of fit to a nonmetric hypothesis, Psychometrika, 1964a, 29, 1-27.

KRUSKAL, J. B. Nonmetric multidimensional scaling: A numerical method. Psychometrika, 1964b, 29, 115-129.

SHEPARD, R. N. The analysis of proximities: Multidimensional scaling with an unknown distance function. 1. Psychometrika, 1962a, $27,125-140$.

SHEPARD, R. N. The analysis of proximities: Multidimensional scaling with an unknown distance function. II. Psychometrika, 1962b, 27, 219-246.

SHEPARD, R. N. Metric structures in ordinal data. Joumal of Mathematical Psychology, $1966,3,287-315$

SHEPARD, R. N., \& CHIPMAN, S. Second-order isomorphism of internal representations: Shapes of states. Cognitive Psychology, 1970, 1, 1-17.

TORGERSON, W. S. Theory and methods of scaling. New York: Wiley, 1958.
TORGERSON, W. S. Multidimensional scaling of similarity. Psychometrika, 1965, 30, 379-393.

\section{NOTES}

1. This work was supported in part by grants to the MINNEMAST center at the University of Minnesota from The National Science Foundation (GE-3), and in part by grants to the University of Minnesota Center for Research in Human Learning from the National Science Foundation (GS-1761), the National Institute of Child Health and Human Development (HD-01136-04), and from the Graduate School of the University of Minnesota.

2. The authors would like to express their appreciation to Roger N. Shepard for his helpful comments on an earlier draft of this paper.

3. power $(p)=d / d t\left(\int \mathrm{md}^{2} \mathrm{x} / \mathrm{dt}^{2} \mathrm{dx}\right)$, work $(w)$ $=\int \mathrm{md}^{2} \mathrm{x} / \mathrm{dt}^{2} \mathrm{dx}$, force (f) $=\mathrm{md}^{2} \mathrm{x} / \mathrm{dt}^{2}$, momentum $(M)=\mathrm{mdx} / \mathrm{dt}$, acceleration (a) $\mathrm{d}^{2} \mathrm{x} / \mathrm{dt}^{2}$, velocity $(\mathrm{v})=\mathrm{dx} / \mathrm{dt}$.

\title{
On the asymmetry of the phase-difference function in binocular flicker
}

\section{C. CORBALLIS, ${ }^{1}$ McGill University, Montreal, Canada}

Foley and Stager have reported that, for right-eye dominant $S s$, the function relating critical flicker frequency (CFF) to the phase lag of pulses to the left eye behind pulses to the right eye is concave downwards for lags between 0 and 180 deg and concave upwards between 180 and 360 deg. This implies a cyclic function such that maximum and minimum CFFs occur not at but slightly above 0 and $180 \mathrm{deg}$, respectively, which in turn suggests faster processing of information to the left than to the right eye. A possible explanation is that the two cerebral hemispheres contributed differently to the resolution of flicker, with the more important contribution coming from the right hemisphere.

Binocular critical flicker frequency (CFF) varies as a function of interocular phase difference. When the pulses to each eye are exactly in phase (0-deg phase difference), CFF is higher than when they are completely out of phase (180-deg phase difference) (Baker \& Bott, 1951; Kinsbourne \& Coughlin, 1969; Perrin, 1954; Thomas, 1955). There is also evidence that the phase-difference function is asymmetrical. Foley \& Stager (1965) reported two experiments in which each pulse to the left eye was made to lag behind the corresponding pulse to the right eye in 45-deg steps, ranging from 0 to $180 \mathrm{deg}$ in one experiment and from 180 to $360 \mathrm{deg}$ in the other. The data, averaged over six Ss in the first experiment and over five $S s$ in the second, are shown in Fig. 1. It can be seen that the function is concave downwards between 0 and $180 \mathrm{deg}$ and concave upwards between 180 and $360 \mathrm{deg}$. All Ss were female, right-eye dominant, and four of them served as Ss in both experiments. Further details can be obtained from Foley and Stager's original report.

Foley and Stager interpret the asymmetry of the function as evidence that neural impulses from the right eye are given more weight at some central locus than neural impulses from the left eye. Thus the difference in CFF between 0 and $45 \mathrm{deg}$ is rather small, because at $45 \mathrm{deg}$ an impulse from the nondominant left eye arrives during an "on" phase for the dominant right eye, and consequently has little effect. By contrast, the difference between 315 and $360 \mathrm{deg}$ is relatively large, because at $315 \mathrm{deg}$ the left-eye impulse arrives centrally during a right-eye "off" phase, and so has a greater effect in reducing CFF. This account is plausible only if special prominence is given to the neural impulses generated by the onset of light to the left eye, since exactly the opposite argument would hold for neural impulses initiated by the offset of light.

\section{AN ALTERNATIVE \\ INTERPRETATION}

Foley and Stager explicitly reject a suggestion by Sampson (1962) that the phase-difference function depends on differences between the eyes in the time taken centrally to integrate information. According to Sampson, information to the left eye is integrated more slowly than that to the right eye, so that when light pulses are in phase peripherally the corresponding neural impulses are out of phase centrally, and when they are out of phase peripherally they are in phase centrally. This suggestion is implausible on two counts: First, it suggests that CFF is highest when flicker is out of phase centrally, whereas on intuitive grounds, at least, one would expect the opposite; and secondly, it implies that the difference in integration time between the two eyes is equal to the period of one semicycle of flicker, which is improbable. Nevertheless, Foley and Stager's data can be taken as evidence for interocular differences in processing time, though not quite in the manner that Sampson proposed.

The data points in Fig. 1 suggest a cyclic function that is displaced slightly to the right, so that maximum and minimum CFF might be said to occur, not precisely at 0 and $180 \mathrm{deg}$, respectively, but slightly above these values. This is consistent with the notion that left-eye information is processed somewhat more rapidly than right-eye information, and that a slight delay of input to the left eye is therefore necessary to restore symmetry centrally. To examine this idea in more detail, equations of the form $Y=a \cos (X-b)+c$ were fitted to the data for each $S$ in each experiment by the method of least squares. $Y$ represents $C F F$, and $X$ the interocular phase difference. The calculated constants, a, b, and c, are shown in Table 1 , and the continuous curves plotted in Fig. 1 are the averaged curves derived from the fitted equations.

Table 1 indicates that in every case but one the constant $b$ is positive, which can be interpreted to mean that processing of left-eye information was faster than that of right-eye information. The actual time differences may be estimated from the formula

$$
t=\frac{1000 \times b}{360 \times c} \mathrm{msec}
$$

and these values are also shown in Table 1. These time differences could have arisen from two sources. They could reflect a bias in the calibration of the equipment, so that when the setting was at $0 \mathrm{deg}$, for example, the actual interocular phase difference was slightly positive. Alternatively, they could have occurred in the processing of information by the Ss, as suggested above. The fact that the time lags for Ss 1,2 , and 5 were fairly consistent between experiments, compared with the relatively 


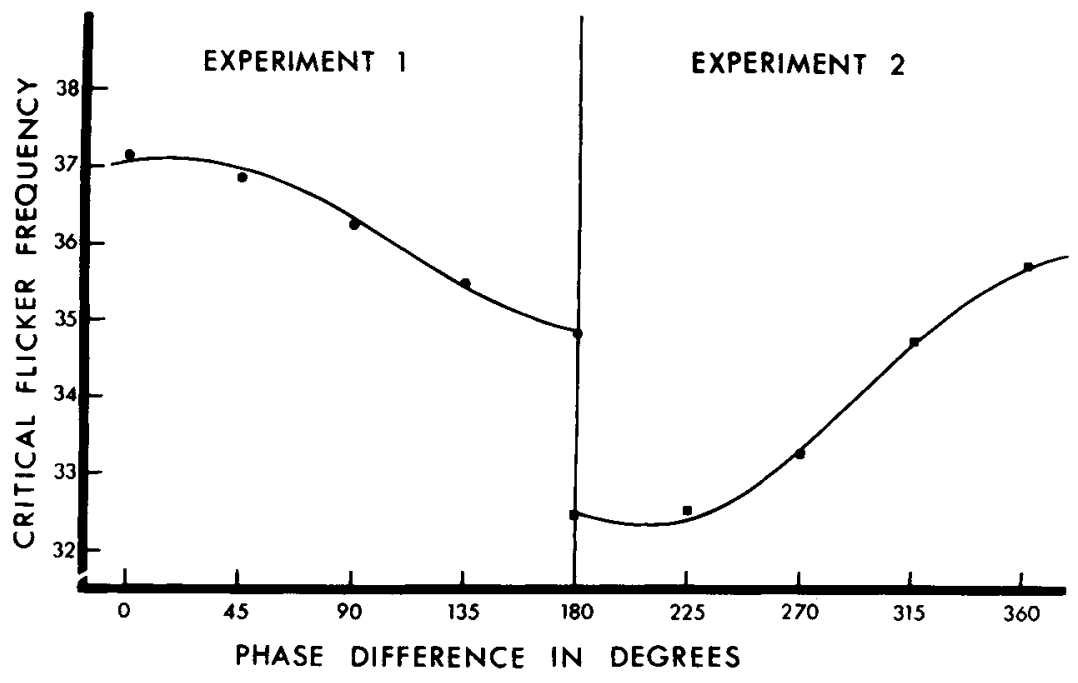

large variability between Ss, suggests that they were a function of the Ss rather than of the equipment. However, S 3 showed widely discrepant lags between the two experiments.

It is possible that the time differences arose from interocular differences in retinocortical transmission time, which in turn might have been due to cortical asymmetry of function. Thus, faster transmission from the left eye could mean that the hemispheres contributed differently to the resolution of flicker, with the right hemisphere providing the more important contribution. This presupposes that contralateral retinocortical projection is faster than ipsilateral projection, so that the fastest and most efficient path to the right hemisphere would be the contralateral path from the left eye. Bower (1966) has estimated that the difference in transmission time between contralateral and ipsilateral projection is about $1.5 \mathrm{msec}$, which is roughly of the same order as the lags shown in Table 1. However, the suggestion that the right hemisphere contributes more critically than the left to

Table 1

Constants Obtained by Fitting Cosine Function to Foley \& Stager's (1965) Data Relating Critical Flicker Frequency to Interocular Phase Difference

\begin{tabular}{|c|c|c|c|c|c|c|c|c|c|}
\hline \multicolumn{5}{|c|}{ Experiment $1(0-180 \mathrm{deg})$} & \multicolumn{5}{|c|}{ Experiment $2(180-360 \mathrm{deg})$} \\
\hline Subject & $\mathbf{a}$ & $b$ & c & t. & Subject & $\mathbf{a}$ & b & c & $\mathbf{t}$ \\
\hline $\begin{array}{l}1 \\
2 \\
3 \\
4 \\
5 \\
6\end{array}$ & $\begin{array}{r}1.89 \\
1.46 \\
.50 \\
1.03 \\
.82 \\
1.39\end{array}$ & $\begin{array}{r}35.4 \\
31.4 \\
-6.1 \\
7.5 \\
2.7 \\
5.0\end{array}$ & $\begin{array}{l}29.36 \\
40.54 \\
31.10 \\
44.22 \\
43.88 \\
26.76\end{array}$ & $\begin{array}{r}3.35 \\
2.15 \\
-.55 \\
.47 \\
.17 \\
.52\end{array}$ & $\begin{array}{l}1 \\
2 \\
3 \\
5 \\
7\end{array}$ & $\begin{array}{l}2.46 \\
2.49 \\
1.38 \\
1.44 \\
1.35\end{array}$ & $\begin{array}{r}32.8 \\
37.5 \\
24.6 \\
7.5 \\
16.6\end{array}$ & $\begin{array}{l}24.73 \\
46.07 \\
32.17 \\
40.12 \\
27.57\end{array}$ & $\begin{array}{r}3.68 \\
2.26 \\
2.12 \\
.52 \\
1.67\end{array}$ \\
\hline
\end{tabular}

Fig. 1. Mean CFFs for each angular phase difference from two experiments by Foley \& Stager (1965). Fitted curves obtained by averaging cosine functions fitted to the data for individual Ss.

the resolution of flicker in right-eye dominant $\mathrm{Ss}$ is somewhat at odds with Efron's (1962) conclusion that perception of simultaneity is a function primarily of the left hemisphere in right-handed Ss. On the other hand, there is increasing evidence that the right hemisphere plays a dominant role in many perceptual, nonverbal tasks (Millikan \& Darley, 1967), of which flicker resolution could be just another example.

\section{REFERENCES}

BAKER, C. H., \& BOTT, E. A. Effects of timing of visual stimuli on binocular fusion and flicker. Canadian Journal of Psychology, 1951, 5, 9-17.

BOWER, T. G. R. A local sign for depth. Nature, $1966,210,1081-1082$.

EFRON, R. The effects of handedness in the perception of simultaneity and temporal order. Brain, 1963, 86, 261-285.

FOLEY, P. J., \& STAGER, P. The phase difference function in binocular flicker. Canadian Journal of Psychology, 1965, 19, 47-55.

KINSBOURNE, M., \& COUGHLIN, P. J. The demonstration of dichoptic flicker effects by the use of polaroid. Quarterly Journal of Experimental Psychology, 1969, 21, 67-68.

MILLIKAN, C. H., \& DARLEY, F. L. (Eds.) Brain mechanisms underlying speech and language. New York: Grune \& Stratton, 1967.

PERRIN, F. M. A study in binocular flicker. Journal of the Optical Society of America, $1954,44,60-69$.

SAMPSON, $H$. Binocular interaction in serial adding. Australian Journal of Psychology, $1962,14,9-21$

THOMAS, G. J. A comparison of uniocular and binocular critical flicker frequencies: Simultaneous and alternate flashes. American Journal of Psychology, 1955, 68, 37-53. NOTE

1. Present address: Department of Psychology, McGill University, Montreal, Quebec. 